\title{
Hospital Admissions and Mortality in Patients with Rheumatic Heart Disease in Brazil: An Analysis from 2008 to 2018
}

\section{Mariana Silva Nunes ${ }^{1}$, Gustavo Tedde-Filho', João Carlos Geber-Júnior ${ }^{2}$, Willian Darwin Júnior ${ }^{3}$, Viviane Uliane Peterle ${ }^{4}$, Ana Paula Monteiro Gomides 4 (i)}

\author{
${ }^{1}$ Academic of Centro Universitário de Brasília, Brasília, Brazil \\ ${ }^{2}$ Medical Clinic Department of Universidade de São Paulo, São Paulo, Brazil \\ ${ }^{3}$ Universidade de São Paulo, São Paulo, Brazil \\ ${ }^{4}$ Centro Universitário de Brasília, Brasília, Brazil \\ Email: ^mariananuneis@gmail.com, gustavo.gtf@hotmail.com, j.geber@hc.fm.usp.br, darwin@usp.be, \\ vivianepeterle@hotmail.com, anapmgomides@gmail.com
}

How to cite this paper: Nunes, M.S. Tedde-Filho, G., Geber-Júnior, J.C., Júnior, W.D., Peterle, V.U. and Gomides, A.P.M. (2020) Hospital Admissions and Mortality in Patients with Rheumatic Heart Disease in Brazil: An Analysis from 2008 to 2018. Advances in Infectious Diseases, 10, 176-180. https://doi.org/10.4236/aid.2020.104015

Received: July 3, 2020

Accepted: September 15, 2020

Published: September 18, 2020

Copyright $\odot 2020$ by author(s) and Scientific Research Publishing Inc. This work is licensed under the Creative Commons Attribution International License (CC BY 4.0).

http://creativecommons.org/licenses/by/4.0/ (c) (i) Open Access

\begin{abstract}
Introduction: The Rheumatic Fever (RF) is a systemic inflammatory disease, caused by Group A beta-hemolytic Streptococcus, predominating in children and adolescents. The clinical manifestations are varied and included in Jones Criteria for diagnosis. The cardiac manifestations are the most relevant, causing severe sequelae such as valvulitis. The RF is still a major public health problem in developing countries despite its primary prophylaxis being simple and effective if well applied. The overall objective of this study was to evaluate the number of hospital admissions and deaths in Brazil from 2008 to 2018. Methodology: Cross-sectional, descriptive, quantitative, documentary study with database provided by the Health Informatics Department of the Brazilian Ministry of Health (DATASUS). Results: In the studied period, a higher prevalence was observed among females (48,232 hospitalizations) and in the adult age group (59,270 hospitalizations and 3972 deaths). The total number of hospitalizations was 83,209 and the total number of deaths was 6572 . The total mortality rate was 7.84. The region with the highest number of hospitalizations was the Southeast (22,863 hospitalizations). The total amount spent in hospitalizations was $\mathrm{R} \$ 879,676,458.63$, with an average value per hospitalization of $\mathrm{R} \$ 10,496.21$. The average length of stay was 12.7 days. Conclusion: Rheumatic heart disease is an important cause of hospitalizations in Brazil. Measures of early diagnosis and adequate treatment should be strongly stimulated.
\end{abstract}

\section{Keywords}

Rheumatic Heart Disease, Hospitalizations, Number of Deaths 


\section{Introduction}

The Rheumatic Fever (RF) is a systemic inflammatory disease caused by a complication of oropharyngeal infection by Group A beta-hemolytic Streptococcus, Streptococcus pyogenes, that affects people with genetic predisposition. The disease is not associated with gender or race; however, it is believed that the prevalence of RF is around 3\% among adolescents and children, predominating between 5 and 15 years of age [1] [2].

The RF clinical manifestations are varied, this can be explained because the infected individual's immune response and are beyond its genetic predisposition [3]. Carditis is the most severe manifestation in patients with rheumatic fever. It occurs in $40 \%-70 \%$ of the first outbreaks, usually arising at an early stage and being diagnosed in the first weeks of the acute phase. Pancarditis and valve lesions characterize the cardiac manifestation of rheumatic fever [4] [5] [6].

In the world, 500.000 new cases of RF are reported per year, the prevalence of carditis is 15 million cases secondary to the disease and as well as 233.000 cases of death at the same time. In Latin America, 21.000 new cases of RF are annually reported. In Brazil, data are scarce. It is estimated that $40 \%$ of cardiac surgeries are performed due to complications of RF [3].

In 2002, 5.000 new cases were reported (Brazilian Institute of Geography and Statistics-IBGE) and it was noticeable a prevalence among children and adolescents. Despite the negative consequences caused by RF in Brazil, we have very few published studies on the subject [3].

The objective of this study was to evaluate the number of hospitalizations of patients with rheumatic heart disease in Brazil and the number of deaths of this population from 2009 to 2018 [2].

\section{Methodology}

This study, we obtained data referring to hospital morbidity provided by Health Informatics Department of the Brazilian Ministry of Health (DATASUS) from the Brazilian Unified Health System (SUS). Information on RF hospitalizations, categorized by tenth International Classification of Diseases (I00 - I02 codes), from January 2008 to December 2018 was collected in patients aged 0 to 80 and over.

For the analyses we used: number of hospitalizations, hospital costs, age group, mean value for hospitalization, gender, average hospital stay. Data from across the country were assessed by region, age group and sex.

The resulting data were subjected to statistical analysis (descriptive measures) with Statistical Package for the Social Sciences Software. As it is a study of public domain data, there was no need for submission to the local ethics committee.

\section{Results}

Among the variables analyzed, the total number of hospitalizations in the period from 2008 to 2018 was 83.209. The largest number of hospitalizations occurred in the age group 25 - 64 years, with approximately 59 thousand hospitalizations 
and a mortality rate of $6.7 \%$. However, the highest mortality rate was found in the population aged 65 and over, reaching $14.71 \%$. The number of hospitalizations by age group, as well as the number of deaths and mortality rate, can be observed in Table 1.

Concerning the regions of Brazil, we observed a greater number of hospitalizations in the Southeast region. There was a higher prevalence of cases of rheumatic fever in the southeast and northeast regions, which made up $68.8 \%$ of total hospitalizations. The distribution of cases by geographic region can be observed in Table 2.

The highest prevalence in the number of hospitalizations was in females. The number of hospitalizations by sex can be observed in Table 3.

Some data related to the disease costs were analyzed. The total amount spent on hospitalizations in this period was $\mathrm{R} \$ 879,676,458.63$, with an average amount per hospitalization of $\mathrm{R} \$ 10,496.21$. The average length of stay was of 12.7 days.

\section{Discussion}

The study evaluated the number of hospitalizations in the period from 2008 to

Table 1. Relation of number of hospitalizations, deaths and mortality rate due to rheumatic fever in Brazil from 2008 to 2018 by age group.

\begin{tabular}{cccc}
\hline AGE GROUP & HOSPITALIZATIONS & DEATHS & MORTALITY RATE \\
\hline TOTAL & 83.809 & 6.572 & $7.84 \%$ \\
Children ( -14 years of age $)$ & 3.556 & 65 & $1.82 \%$ \\
Youth $(14-24$ years of age $)$ & 5.396 & 242 & $4.48 \%$ \\
Adults $(25-64$ years of age $)$ & 59.279 & 3.972 & $6.70 \%$ \\
Elderly $(>65$ years of age $)$ & 15.578 & 2.293 & $14.71 \%$ \\
\hline
\end{tabular}

Table 2. Number of hospitalizations due to rheumatic fever from 2008 to 2018 by regions of Brazil.

\begin{tabular}{cc}
\hline REGION & HOSPITALIZATIONS \\
\hline TOTAL & 83.809 \\
North & 3.777 \\
Northeast & 22.863 \\
Southeast & 34.855 \\
South & 13.542 \\
Midwest & 8.772 \\
\hline
\end{tabular}

Table 3. Number of hospitalizations due to rheumatic fever from 2008 to 2018 by sex.

\begin{tabular}{cc}
\hline SEX & HOSPITALIZATIONS \\
\hline TOTAL & 83.209 \\
Males & 35.577 \\
Females & 48.232 \\
\hline
\end{tabular}


2018. We saw that the number of hospitalizations was 83.209. It was not found other studies related to hospitalization by RF in Brazil for comparison. However, it is estimated that $40 \%$ of cardiac surgeries in Brazil are performed due to complications of RF2. According to IBGE, in the year 2002, 5.000 new cases of the disease were reported [3].

The number of hospitalizations by age group showed a predominance among adults, a fact compatible with the natural progression of the disease, since the acute phase is common in children, but the complications occur predominantly in the adult age group, when the disease is in its chronic phase [1]. It is worth mentioning that this high number of adult patients is part of the working age population, which can cause significant socioeconomic repercussions among these patients.

Regarding the number of deaths, this study found a total of 6.572 deaths in this period. According to current literature, the number of deaths worldwide reaches 233.000 per year. The study also pointed out a mortality rate of 7.84 in the period. This datum is similar to what can be found in the literature, which shows that the mortality rate from chronic rheumatic disease (CRC) went from 5.77 in 1998, to 8.22 in 2016 (growth of $42.5 \%$ ) [7].

Another datum that arose from our study was the higher prevalence within female population; however, a study that proves prevalence among sexes has not been published yet.

When demographic Brazilian regions were analyzed, we found out that the region with the highest number of hospitalizations was Southeast Brazil; however, this figure is not supported by data in the current literature. It is worth noticing that such high numbers can be linked to the fact that Southeast Brazil is the most populous region (IBGE, 2019), or because it is a region where disease report is more efficient when compared to others [8].

As for the disease treatment costs in the period under analysis, the total hospitalization costs exceeded 800 million reais, with an average of more than 10 thousand reais per hospitalization. A study carried out between 1998 and 2016 showed an increase of $265 \%$ in costs with hospitalizations due to chronic rheumatic disease (CRC). This indicates an ever-increasing cost to the Brazilian healthcare system because of this condition [7].

The study also revealed an average length of stay of 12.7 days. When compared to congenital heart disease in Brazil, literature demonstrates that the length of stay of these patients is about 16 days in the Intensive Care Unit (ICU). This indicates that the average length of stay due to rheumatic heart disease can be said to be one of the most frequent reasons for pediatric cardiology emergencies in Brazil [9].

This study's main limitation was the shortage of available data on the topic. We had some difficulties comparing the gathered data with pre-existing ones. Besides that, another restricting aspect was that cases of RF were probably underreported. Even in the reported cases, patients' information, disease details, and treatment procedures were incomplete. Even so, we consider the findings to 
be extremely relevant to the public healthcare.

\section{Conclusions}

This study revealed a higher number of hospitalizations due to chronic rheumatic heart disease in Brazil between 2008 and 2018.

These data may be regarded as an indicator of the importance of RF's early diagnosis and treatment in order to reduce chronic complications, death and consequently cause a positive impact on individual and collective health.

\section{Conflicts of Interest}

The authors declare no conflicts of interest regarding the publication of this paper.

\section{References}

[1] Burke, R.J. and Chang, C. (2014) Diagnostic Criteria of Acute Rheumatic Fever. Autoimmunity Reviews, 13, 503-507. https://doi.org/10.1016/j.autrev.2014.01.036

[2] Kumar, R.K. and Tandon, R. (2013) Rheumatic Fever \& Rheumatic Heart Disease: The Last 50 Years. The Indian Journal of Medical Research, 137, 643.

[3] Peixoto, A., Linhares, L., Scherr, P., Xavier, R., Siqueira, S.L., Pacheco et al. (2011) Febre reumática: Revisão sistemática. Revista da Sociedade Brasileira de Clínica Médica, 9, 234-238.

[4] Roberts, S., Kosanke, S., Dunn, S.T., Jankelow, D., Duran, C.M.G. and Cunningham, M.W. (2001) Pathogenic Mechanisms in Rheumatic Carditis: Focuson Valvular Endothelium. The Journal of Infectious Diseases, 183, 507-511. https://doi.org/10.1086/318076

[5] Marijon, E., Ou, P., Celermajer, D.S., Ferreira, B., Mocumbi, A.O., Sidi, D., et al. (2008) Echocardiographic Screening for Rheumatic Heart Disease. Bulletin of the World Health Organization, 86, 81-160. https://doi.org/10.2471/BLT.07.046680

[6] Pereira, B.Á.F., Belo, A.R. and Silva, N.A. (2017) Rheumatic Fever: Updating Jones criteria in Light of the American Heart Association Review-2015. Revista Brasileira de Reumatologia, 57, 364-368. https://doi.org/10.1016/j.rbr.2016.12.005

[7] Figueiredo, E.T., Azevedo, L., Rezende, M.L. and Alves, C.G. (2017) Febre Reumática: uma doença sem cor. Arquivos Brasileiros de Cardiologia, 113, 345-354.

[8] Brazilian Institute of Geography and Statistics (IBGE) (2020) Projection of the Population of Brazil and of the Units of the Federation. https://www.ibge.gov.br/apps/populacao/projecao/

[9] Belo, W.A., Oselame, G.B. and Neves, E.B. (2016) Perfil clínico-hospitalar de crianças com cardiopatia congênita. Cadernos Saúde Coletiva, 24, 216-220. https://doi.org/10.1590/1414-462X201600020258 